\title{
Konservasi Nisan Putro Balee dan Tgk. Awe Geutah Di Kabupaten Pidie, Provinsi Aceh
}

\author{
Oleh Masnauli. \\ Balai Pelestarian Cagar Budaya Banda Aceh \\ Email : masnauli_bp3@yahoo.com
}

\begin{abstract}
Abstrak : Konservasi nisan Putro Balee dan Tgk Awe Geutah di Kabupaten Pidie, Provinsi Aceh merupakan salah satu kegiatan pemeliharaan terhadap cagar budaya. Upaya pemeliharaan ini dilakukan untuk mengurangi atau menghambat kerusakan yang terjadi pada makam. Kerusakan atau pelapukan dapat diakibatkan oleh pertumbuhan jamur, lumut, akumulasi debu, lumut, gempa bumi, gelombang tsunami dan lain-lain. Kegiatan konservasi yang dilakukan adalah pembersihan mekanis kering dan basah. Konservasi berupa pembersihan mekanis kering dilakukan dengan cara membersihkan kotoran, akumulasi debu, lumut yang menempel dengan sikat, sudip bambu, tusuk sate dan kuas. Pembersihan mekanis basah dilakukan dengan cara membersihkan jamur dan lichen yang menempel dengan menyiran air keseluruh permukaan makam, sambil disikat secara perlahan-lahan sampai semua jamur dan lichen hilang. Setelah pekerjaan ini selesai, makam yang patah gempil diperbaiki dengan cara penyambungan tanpa angkur. Nisan yang miring dan melesak ditegakkan dan diperkuat bagian kakinya. Bagian puncak nisan yang ditempel dengan semen dibersihkan bagian semennya dengan cara diketok perlahan-lahan sampai bersih dan tidak merusak nisan.
\end{abstract}

Kata Kunci : Makam, konservasi, nisan

\begin{abstract}
Conservation Putro Balee and Tgk Awe Geutah gravestones in Pidie Regency, Aceh Province is one of activities conducted for cultural heritage preservation. The conservation is conducted to slow down the damage happened at the gravestones. The damage is caused by lichen, dust moss, earthquake, tsunami, and others. Activities conducted are dry and wet mechanical conservation. Dry mechanical conservation is conducted by cleaning waste, dust, and moss using brush and sharpened bamboo. Wet mechanical conservation is conducted to clean lichen by spraying water into the gravestone surface. The spraying is accompanied by slowly brushing lichen until it is disappear. After the cleaning is done, crack and broken gravestones are fixed without using anchor. Leaning gravestones are fixed to the original position and strengthened. The cement that stuck in the gravestones is cleaned by tapping the cement slowly until it flakes but without damaging the gravestones
\end{abstract}

\section{Pendahuluan}

Di Provinsi Aceh banyak ditemukan makam kuno Islam yang mempunyai nilai sejarah tinggi seperti komplek makam Putro Balee dan Awe Geutah di Kabupaten Pidie, sehingga sangat penting untuk dijaga kelestariannya dengan cara mengkonservasinya. Namun demikian evaluasi terhadap hasil konservasi tersebut belum banyak dilakukan, oleh karena itu pada makalah ini akan dikemukakan hasil evaluasi terhadap konservasi yang telah dilakukan oleh BPCB Aceh. Kegiatan ini merupakan kegiatan pemeliharaan yang dilakukan oleh BPCB Aceh, dan makalah ini merupakan ringkasan dari laporan kegiatan. Ringkasan laporan kegiatan konservasi Makam Putro Balee dan Tgk. Awe geutah ini dipublikasikan supaya ada masukan dan kritikan yang sangat berguna bagi penulis sebagai bahan acuan yang lebih baik dalam kegiatan konservasi berikutnya.

Nisan-nisan Putro Balee dan Tgk. Awe Geutah telah mengalami kerusakan diantaranya patah, miring, melesak, rapuh, kotor, akumulasi debu, berjamur, berlumut dan keropos. Terdapat pula kerusakan yang diakibatkan oleh kesengajaan manusia (vandalisme) yaitu penambalan semen pada pundak nisan bagian kepala yang sebelumnya patah (hilang). Upaya untuk melestarikan cagar budaya yang sering dilakukan oleh BPCB Aceh dalam menangani masalah kerusakan adalah konservasi. Konservasi sudah berkali-kali dilaksanakan dalam kegiatan rutin tahunan Balai Pelestarian Cagar Budaya karena telah dirasakan manfaatnya. Khusus di Provinsi Aceh dan Sumatera Utara konservasi bahan batu khususnya dilakukan pada nisan atau jirat. Penulis akan membahas mengenai konservasi pada nisan Putro Balee dan nisan Awe Geutah yang ada di Kabupaten Pidie, Provinsi Aceh.

Istilah konservasi di sini bukan istilah yang biasa digunakan dalam berbagai bidang, misalnya kehutanan, lingkungan, energi hingga kedokteran, tetapi yang dimaksud dengan konservasi disini adalah dalam bidang pelestarian cagar budaya. Pengertian konservasi dalam 
arti luas adalah segala macam upaya untuk melestarikan termasuk pelindungan, pemanfaatan, dan pengembangan. Dengan demikian konservasi dalam arti luas memiliki cakupan yang sangat luas, atau bisa diartikan sebagai preservasi atau pelestarian itu sendiri. Sedangkan konservasi dalam arti sempit adalah usaha-usaha untuk mempertahankan kelestarian material cagar budaya termasuk nilai-nilai yang terkandung yang mencakup tindakan pemeliharaan, treatment, dan pengawetan. Konservasi dalam arti sempit lebih cenderung pada kegiatan teknis yang melibatkan material cagar budaya dan bahan-bahan kimia konservannya. (Cahyandaru, 2010.

Konservasi adalah tindakan pelestarian yang diambil untuk memelihara dan mengawetkan cagar budaya dengan teknologi modern (bahan dan alat) sebagai upaya untuk menghambat proses kerusakan dan pelapukan lebih lanjut. Kebijakan untuk melaksanakan pemeliharaan terhadap cagar budaya terdapat pada Undang-undang Republik Indonesia Nomor 11 Tahun 2010 tentang Cagar Budaya pasal 75 dan pasal 76 (Undang - Undang No.11 Tahun 2010).

Perawatan cagar budaya dapat dilakukan dengan dua cara yaitu perawatan preventif (perawatan sehari-hari dan pengendalian lingkungan atau mikroklimatologi) dan perawatan kuratif (perawatan dengan metode tradisional dan modern). Perawatan cagar budaya/situs harus dilakukan dengan perencanaan yang sistematis, terpadu, dan berkesinambungan. Dengan upaya perawatan yang konseptual diharapkan kondisi keterawatan cagar budaya akan tetap terjaga dengan baik sehingga cagar budaya/ situs dapat dikembangkan sebagai aset budaya nasional serta dapat diwaristeruskan kepada generasi yang akan datang (Tim Penyusun Pedoman, 2005).

Dalam kegiatan perawatan cagar budaya selain terdapat landasan operasional yang mengacu pada peraturan perundangan yang berlaku di Indonesia, konvensi dan kesepakatan internasional, juga harus memperhatikan beberapa prinsip dasar yang digunakan dalam perawatan cagar budaya. Secara garis besar ada dua prinsip yang harus diperhatikan, yaitu prinsip arkeologis dan teknis. Tata urut penanganan perawatan cagar budaya harus sesuai dengan kedua prinsip tersebut supaya dalam pelaksanaannya tidak terjadi kesalahan prosedur. Dengan demikian maka prosedur dalam perawatan cagar budaya benar-benar dapat dipertanggungjawabkan secara ilmiah. Oleh karena itu dalam pelaksanaan perawatan cagar budaya perlu wawasan penelitian sehingga aspek kesejarahan, ilmu pengetahuan, dan kebudayaan yang terkandung pada cagar budaya dapat terungkap. Selain berdasarkan kedua prinsip tersebut aspek yang tidak dapat dikesampingkan untuk keberhasilan dalam perawatan cagar budaya adalah aspek sosial yaitu peran serta masyarakat. Dalam hal ini seyogyanya perlu :

a. memperhatikan dan mempertimbangkan kepentingan dan pandangan (persepsi) masyarakat;

b. memberdayakan potensimasyarakatdan meningkatkan peran serta masyarakat sehingga tercipta rasa memiliki tanggung jawab dalam upaya pelestarian dan kelestarian cagar budaya tersebut.

Nisan Putro Balee dan Awe Geutah merupakan cagar budaya tidak bergerak yang memerlukan penanganan perawatan, baik perawatan preventif maupun perawatan kuratif mengingat nisan-nisan ini belum pernah dikonservasi. Pemeliharaan yang dilakukan selama ini hanya sebatas membersihkan rumput dan daun-daunan oleh juru pelihara. Perawatan preventif adalah tindakan untuk mencegah cagar budaya agar terhindar dari faktor-faktor penyebab proses pelapukan dan kerusakan. Perawatan kuratif adalah tindakan dalam rangka penanggulangan kerusakan dan pelapukan cagar budaya. Perawatan kuratif dapat berupa metode perawatan tradisional dan modern. Perawatan tradisional dilakukan dengan cara sederhana dengan menggunakan bahan tradisional. Sedangkan perawatan modern adalah perawatan dengan menggunakan bahan kimia, dan umumnya menggunakan prosedur perawatan yang baku. Perawatan modern meliputi:

1. Pembersihan: dimulai dari pembersihan kering, pembersihan basah kemudian dilanjutkan dengan pembersihan kimia. Pembersihan kimia dilakukan untuk menghilangkan noda-noda minyak dan cat atau mematikan pertumbuhan jasad organik seperti algae (ganggang), lumut, lichen (jamur kerak) yang dalam tahap-tahap sebelumnya tidak dapat hilang.

2. Perbaikan: terdiri dari perekatan/pengeleman, penyambungan tanpa angkur, penyambungan dengan angkur, penambalan, penyuntikan (injeksi), dan kamuflase (penyelarasan warna).

3. Konsolodasi: untuk memperkuat ikatan struktur 
bahan cagar budaya yang telah mengalami pelapukan dengan menggunakan bahan konsolodasi.

4. Pengawetan: untuk memperlambat tumbuhnya kembali jasad-jasad organik, seperti algae (ganggang), lumut, lichen (jamur kerak).

5. Pengolesan lapisan kedap air: dilakukan agar cagar budaya terhindar dari kerusakan-kerusakan karena faktor air (Tim Penyusun Pedoman, 2005) .

Pada tindakan konservasi yang secara langsung dilestarikan adalah benda atau materialnya, namun pada dasarnya konservasi bertujuan untuk melestarikan nilainilai pentingnya. Pelestarian nilai penting cagar budaya membawa konsekuensi harus dilestarikannya benda/ materialnya karena nilai penting terkandung dalam bendanya. Konsep ini penting untuk dipahami karena pelestarian benda tanpa memperhatikan nilai penting yang terkandung dapat mengakibatkan kesalahan fokus tindakan menyelamatkan bendanya namun secara tidak disadari nilai penting tidak dipertahankan. Kesalahan yang mungkin terjadi misalnya: tidak diperhatikannya faktor keaslian bahan, teknik pengerjaan, patina, dan faktor intrinsik lainnya. Nilai penting cagar budaya sangat berkaitan dengan konsep tentang otentisitas karena pada dasarnya cagar budaya akan bernilai tinggi hanya jika masih dalam kondisi otentik atau asli (Cahyandaru, 2010).

Pekerjaan konservasi harus memperhatikan aspek otentisitas karena konservasi seringkali menyinggung otentisitas benda. Sebagai contoh penggantian material baru dalam pekerjaan konservasi/pemugaran bangunan batu, bata, kayu, dan lain-lain. Penggantian bahan bisa dibenarkan dan tidak mengganggu otentisitas jika dilakukan dengan hati-hati dan didasarkan pada aturan maupun kaidah-kaidah yang berlaku. Tetapi penggantian pun bisa menyebabkan berkurangnya otentisitas jika mengurangi nilai-nilai penting cagar budaya tersebut. Cagar budaya yang dikonservasi dengan memperhatikan otentisitas secara konsisten akan meningkatkan integritas dari cagar budaya tersebut. Istilah yang sering digunakan terutama dalam pengelolaan warisan budaya dunia adalah otentisitas dan integritas (otenticity and Integrity) (Cahyandaru, 2010).

\section{Pembahasan}

Komplek Makam Putro Balee dan Komplek Makam Tgk. Awe Geutah telah mengalami pelapukan dan kerusakan. Hal ini diakibatkan oleh faktor lingkungan, faktor perencanaan, dan menurunnya rasio kekuatan bahan maupun struktur. Selain itu kerusakan dan pelapukan juga dapat terjadi akibat penurunan rasio kekuatan gaya statis, dinamis, kimia-fisis, jenis material dan struktur bangunan. Sumbangan yang besar terhadap kerusakan dan pelapukan juga disebabkan oleh manusia, bencana alam, iklim, air serta pertumbuhan jasad renik. Proses-proses kerusakan dan pelapukan meliputi mekanis, fisis, kimia dan biologi (Munandar, 2006).

Bahan yang digunakan pada Komplek Makam Putro Balee dan Komplek Makam Tgk. Awe Geutah adalah batu pasir tufaan. Komplek ini berada di Kabupaten Pidie. Kabupaten Pidie termasuk dalam wilayah beriklim tropis basah, temperatur berkisar dari suhu minimum $19^{\circ}$ - $22^{\circ}$ sampai dengan suhu maksimum $30^{\circ}-35^{\circ}$ dengan curah hujan paling tinggi pada bulan Januari sedangkan curah hujan paling tetap terjadi pada bulan Oktober dan Desember.

\section{Data Sejarah}

Situs Komplek Makam Putro Balee berada di Desa Keutapang Sanggue, Kec. Pidie, Kab. Pidie, Prov. Aceh. Komplek ini menempati areal seluas 4,60 x 7,66 meter dengan status tanah wakaf. Istilah Putro Balee atau Putri Janda ini adalah nama yang disebut-sebut kepada tokoh dalam komplek makam ini. Menurut informasi tokoh masyarakat setempat Putro Balee (putri janda) adalah seorang putri yang suaminya telah gugur atau meninggal dunia. Putro Balee ini seorang putri yang berasal dari bangsa Portugis yang dibawa ke Aceh (Pedir) sebagai tawanan. Suaminya telah gugur ketika Portugis diserang dalam peperangan melawan Raja Kerajaan Atjeh. Karena putri jelita ini tidak mempunyai sanak keluarga dan suaminya telah meninggal, maka dia dijuluki dengan "Putro Balee". Disisi lain latar belakang sejarah yang dapat dijelaskan tentang sosok putri ini sebagaimana disebutkan dalam buku "Epigrafi dan Sejarah Nusantara" karangan Louis Charles Darnais mengatakan bahwa Putri Balee disebut dengan Putri Balu, ini merupakan putri dari Sultan Ma'ruf Syah anak Sulaiman Nur. Meninggal hari Rabu 20 Muharram tahun 1562 M. Angka tahun yang 
disebutkan Darnais (peneliti) ini meragukan dan ada silsilah bacaan epigraf di batu nisannya. Menurut Dra. Dahlia yang telah membaca kaligrafi pada saat dilakukan pembersihan mekanis kering dan basah (konservasi) pada nisan Putro Balee menunjukkan angka tahun yang terbaca adalah tahun meninggalnya yaitu: "Tistumiah wattisna min hijriah min yaumil arbain fikesyiamin syahrin muharram" artinya meninggal tahun $990 \mathrm{H}$ pada Hari Rabu tanggal 20 Muharram (BP3, 2012).

Situs Komplek Makam Tengku Awe Geutah berada sekitar 200 meter dari arah Selatan dari jalan protokol Pidie - Medan, yaitu terletak di Desa Ujung Langgo, Kecamatan Pidie, Kabupaten Pidie. Situs ini terletak pada sebidang tanah yang ditinggikan dari tanah sekitarnya yang membujur dari Barat ke Timur, memempati areal seluas 9,20 x 4,57 meter, dengan pagar kawat setengah permanen sebagai pembatas dengan daerah sekitarnya. Tengku Awe Geutah merupakan seorang ulama yang datang ke Pidie mengembangkan agama Islam. Sedangkan makam Tengku Awe Geutah yang berlokasi di Desa Ujung Langgo, Kabupaten Pidie ini menurut tokoh masyarakat setempat adalah salah seorang murid Tengku Awe Geutah dari Bireuen. sebutan istilah dalam ejaan bahasa Aceh Awe (rotan) Geutah (karet/ lengket). Ini adalah sebuah filosofis yang disebutkan oleh orang Aceh yang mengandung pengertian bahwa, seorang ulama menyebarkan agama kemana-mana dan betah dalam mengembangkan syiar agama.

Sebagian tokoh masyarakat Pidie lainnya memberi tanggapan bahwa, Tengku Awe Geutah yang terdapat di Desa Ujung Langgo adalah seorang ulama Islam yang datang dari jazirah Arab yang mengembangkan paham keislamannya di Aceh. Selain mengembangkan pengetahuan Islam dan dakwahnya, keluarga beliau juga mencari nafkah dengan melakukan perdagangan jual beli rotan muda (awe geutab) yang baru ditebang dihutan, selain menyebarkan ajaran Islam beliau juga menampung atau membeli rotan sebagai salah satu usaha menafkahi hidup keluarganya. Dari cikal bakal nama atau tempat kediaman tengku ini maka masyarakat menyebutkan dengan gampong awe geutab saja.

\section{Data Arkeologis}

Situs Komplek Makam Putro Balee terdiri dari 10 buah batu nisan, 1 buah berupa batu bulat polos, nisan-nisan ini tidak utuh lagi dan umumnya telah mengalami kerusakan baik oleh faktor usia maupun oleh manusia (vandalisme). Tipelogi nisan sebagai berikut :

1). Tipe goda, segi delapan dengan puncaknya menyerupai bunga teratai sedang mekar. Setiap segi dibatasi dengan pelipit.

2). Tipe goda, segi delapan polos tanpa motif.

3). Tipe balok, segi empat dengan ukiran kaligrafi pada tiap panel dan bingkai.

4). Tipe pipih bersayap (penataan batu), dengan pola hias beragam khususnya nisan Makam Putro Balee.

5). Tipe goda polos pada ujungnya menyerupai stupa.

Umumnya nisan yang ada di komplek ini tidak ada lagi yang utuh, dengan jumlah makam 10 buah dan bulat polos satu buah yang menunjukkan ciri kekunaannya. Pola hias pada makam ini berupa motif sulur-suluran bunga lidah api dan kaligrafi serta arabes.

Situs Komplek Makam Tengku Awe Geutah terdapat 6 (enam) buah makam dan semuanya tidak memakai jirat, tiga buah makam diantaranya masih dalam kondisi utuh dan yang lainnya dalam kondisi rusak/patah. Makam ini terletak di atas bukit kecil (tanah yang ditinggikan) di dalam kebun milik masyarakat. Di sekelilingnya dipenuhi dengan pohon melinjo. Bentuk nisan pipih segi empat, pipih penata bahu (bersayap) dan balok persegi empat. Tulisan kaligrafi terdapat pada panelpanel di bagian badan nisan. Nisan-nisan di komplek makam ini dimanfaatkan untuk mengasah bisni (pisau) oleh masyarakat. Namun demikian di antara nisan-nisan yang ada, belum terindikasi yang mana mkam tokoh Awe Geutah karena deskripsi yang ada belum dapat terbaca. Yang dapat jelas terbaca hanya berupa kalimat tauhid " $L a$ ilaha illallah Muhammadar Rasulullab" yang paling banyak mengisi pundak-pundak badan nisan.

\section{Identifikasi Kerusakan}

Sebelum pelaksanaan perawatan, didahului dengan kegiatan studi teknis perawatan cagar budaya berbahan batu atau identifikasi jenis kerusakan. Kegiatan ini dilakukan agar pelaksanaan perawatan cagar budaya 


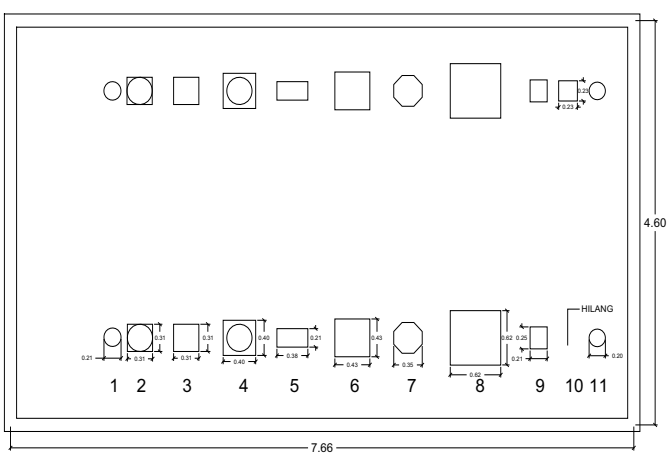

Gambar 1. Denah Komplek Makam Putro Balee

berbahan batu dapat dilaksanakan sesuai dengan prinsip arkeologis dan teknis. Kegiatan studi teknis tersebut meliputi: observasi, identifikasi, dan rencana penanganan. Menurut pengamatan terdapat jenis-jenis kerusakan di Komplek Makam Putro Balee (Gambar 1) antara lain kerusakan secara mekanis, kerusakan secara fisis, kerusakan secara khemis, kerusakan secara biotis. Kerusakan mekanis yaitu kerusakan bahan baku makam yang diakibatkan oleh gaya-gaya mekanis seperti gempa, tekanan, tanah longsor dan banjir. Gejala-gejala yang nampak pada kerusakan ini adalah terjadinya keretakan, kemiringan, melesak, pecah dan kerenggangan pada komponem bahan baku makam atau struktur makam. Kerusakan yang diakibatkan oleh mekanis ini terdapat pada nisan nomor 2, nisan nomor 6 , nisan nomor 7 , nisan nomor 8, dan nisan nomor 10. Kerusakan fisis terjadi akibat naik turunnya suhu dan perbedaan kemampuan memuai (mengembang) dan menyusut dari mineralmineral yang berbeda pada bahan baku (batu) makam, kekuatan yang berbeda mengakibatkan bahan baku makam menjadi rapuh dan mudah hancur. Kerusakan ini terdapat pada nisan nomor 6 , nisan nomor 7, nisan nomor 8. Kerusakan khemis yang terjadi diakibatkan oleh proses hidrolisasi, oksidasi, karbonasi, hidrasi, atau reaksi kimia yang lebih komplek. Kerusakan ini terdapat


Foto 1. Komplek Makam Putro Balee dari arah Utara dan Selatan

pada nisan nomor 9. Pelapukan secara biotis merupakan proses pelapukan batu karena aktivitas makhluk hidup. Kerusakan biotis ini terjadi pada seluruh nisan. Ada beberapa kerusakan nisan yang diakibatkan oleh manusia yaitu batu nisan dijadikan sabagai tempat pengasahan pisau/parang oleh penduduk setempat sehingga batu ini berlubang dan kerusakan lain adalah batu nisan yang ditempel dengan spesi campuran semen dan pasir oleh tukang pada saat dilakukan rehabilitasi dan pemasangan cungkup oleh BRR dan Pemda Pidie.

Jenis-jenis kerusakan di komplek makam Tgk. Awe Geutah (Gambar 2) antara lain Kerusakan mekanis yaitu nisan nomor 1, nisan nomor 2, nisan nomor 3, nisan nomor 4. Kerusakan secara fisis yaitu nisan nomor 5 dan nisan nomor 6. Kerusakan secara khemis tidak ada, kerusakan secara biotis nisan nomor 1 sampai nisan nomor 6 .

Secara garis besar kerusakan yang terjadi pada Komplek Makam Putro Balee dan Komplek Makam Tgk. Awe Geutah adalah retak, pecah, gempil, aus, patah, pengelupasan, dan ulah manusia. Dari hasil pengamatan hampir $80 \%$ nisan-nisan ini ditumbuhi oleh jamur, lichen, lumut dan akumulasi debu. Keberadaan komplek makammakam ini pada daerah yang beriklim tropis lembab dan berada di alam terbuka sehingga mempercepat 



Foto 2. Jenis-jenis kerusakan pada batu nisan di Komplek Makam Putro Balee (retakan, patah, pecah, keropos, berjamur dan lain-lain).

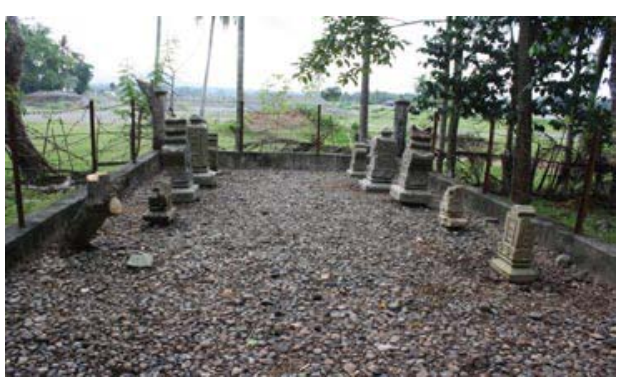

Foto 3. Komplek Makam Awe Geutah

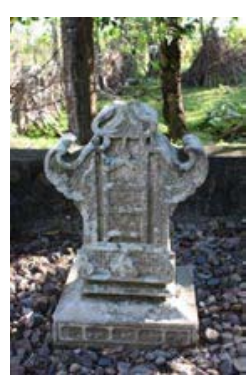

Foto 4. Jenis kerusakan pada batu nisan (retak, patah, jamur, lichen)


pertumbuhan jasad renik seperti lumut, jamur, lichen, dan tumbuhan penumpang lainnnya.

\section{Tindakan Pemeliharaan}

Untuk menanggulangi kerusakan-kerusakan di atas diperlukan tindakan perawatan dan pemeliharaan. Tindakan perawatan yang dilakukan adalah pembersihan, baik mekanis kering maupun mekanis basah, serta perawatan kimiawi. Tindakan perawatan yang dilakukan menggunakan metode tradisional maupun modern. Pelaksanaan perawatan antara lain meliputi pembersihan, perbaikan, penyambungan, penyuntikan (injeksi) kamuflase, konsolidasi, pengawetan, dan pengolesan lapisan kedap air (bila diperlukan).

\section{- Pembersihan}

Pembersihan dilakukan secara tradisional yaitu mekanis kering maupun basah. Sasaran pembersihan secara mekanis pada batu-batu nisan meliputi seluruh permukaan makam, karena pada umumnya seluruh nisan tersebut sudah ditumbuhi jamur, lumut kerak (lichen),

algae dan mikro organisme lainnya. Dalam pelaksanaan kegiatan konservasi tradisional ini menggunakan bahan dan peralatan sebagai berikut: kemoceng/sulak, kuas, sikat ijuk, sikat plastik, sikat gigi, sudip bambu, spatula, sapu lidi, ember dan gayung serta air bersih. Pembersihan secara mekanis kering dilakukan dengan tujuan membersihkan kotoran dan debu yang menempel pada makam, jirat dengan menggunakan kemoceng dan kuas. Selanjutnya nisan-nisan disikat menggunakan sikat ijuk dan sikat plastik halus. Sikat gigi/sudip bambu digunakan pada bagian-bagian yang sulit dijangkau dengan sikat ijuk dan sikat plastik halus. Setelah pembersihan kering selesai, dilanjutkan dengan pembersihan mekanis basah dengan cara menyiram air dengan menggunakan gayung

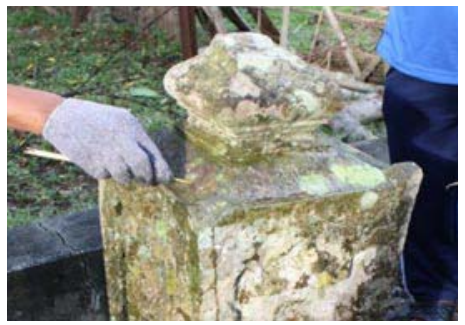

Foto 5. Pembersihan mekanis kering

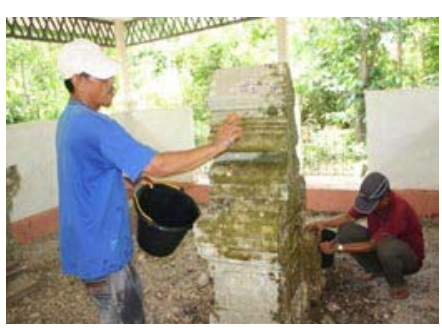

Foto 6. Pembersihan mekanis basah 
mulai dari bagian atas, sambil terus disikat secara perlahan dan merata sampai semua debu, kotoran dan lumut yang menempel hilang (lihat foto 5 dan 6).

\section{- Perbaikan}

\section{a. Penyambungan tanpa angkur}

Setelah pembersihan selesai kegiatan selanjutnya adalah perbaikan pada nisan-nisan yang patah, pecah, dan miring. Perbaikan adalah upaya pemulihan bahan cagar budaya yang telah rusak dengan jalan menambal, menyambung, dan mengganti bagian yang hilang agar bentuknya mendekati keadaan aslinya. Tindakan perbaikan ini terdiri dari perekatan/pengeleman, penyambungan tanpa angkur, penyambungan dengan angkur, penambalan, penyuntikan (injeksi) dan kamuflase. Perbaikan tersebut menggunakan bahan perekat baik organik maupun anorganik. (Tim penyusun pedoman, 2005). Pada Makam Tgk. Awe Geutah terdapat nisannisan yang patah dan pecah, untuk itu perlu diadakan pengeleman dan penyambungan tanpa angkur. Peralatan sebagai berikut: lem Epoxy Resin, scrub, sarung tangan karet, masker, spatula, gagang press, kuas.

\section{Prosedur pengerjaan adalah:}

- Menyiapkan bahan dan alat yang dilakukan, kemudian memakai sarung tangan dan masker.

- Melakukan pencampuran Sikkadur dengan perbandingan $2: 1$. Cara pegadukan yaitu dengan mecampur kedua bahan ini ke dalam wadah dengan hati-hati selama 5 menit, kemudian diaduk hingga campuran merata.

- Setelah dicampur, kedua permukaan pecahan batu nisan diolesi lem tersebut dan disambung kembali (lihat foto 7)

\section{b. Penegakan Batu Nisan Miring}

Pada Komplek Makam Tgk. Awe Geutah terdapat nisan-nisan yang miring dan melesak, untuk itu perlu diadakan penegakan nisan-nisan tersebut. Peralatan sebagai berikut:
- Balok kayu
- Cangkul
- Linggis sedang
- Linggis besar
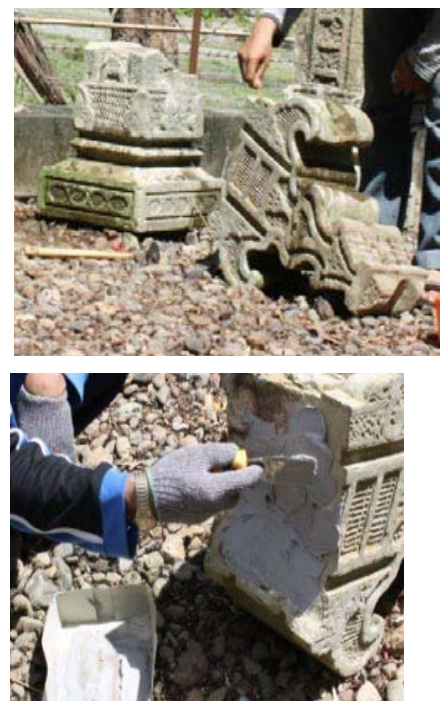

Foto 7. Proses penyambungan tanpa angkur
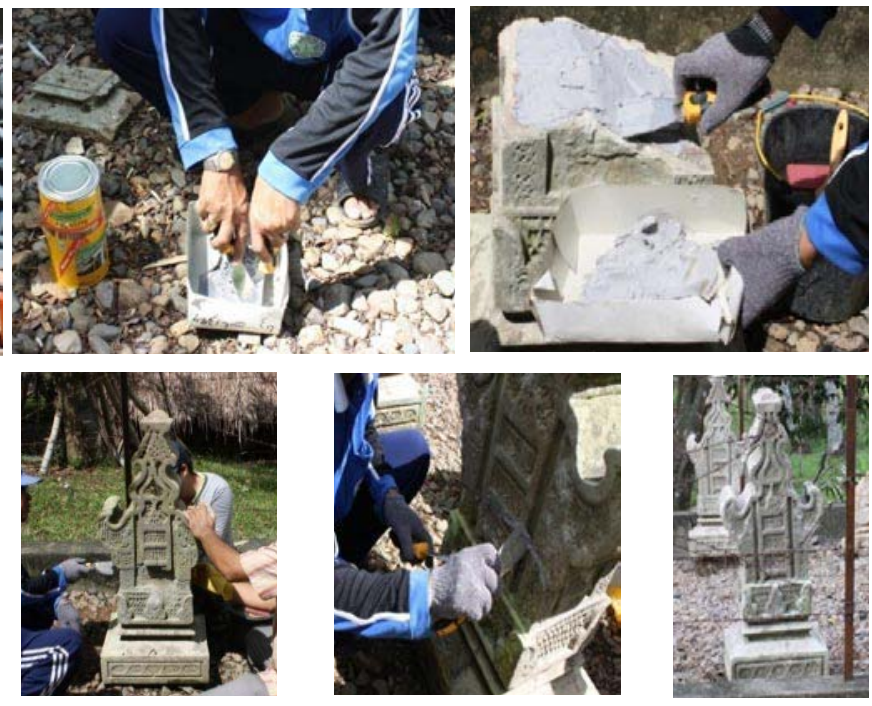

Foto 8. penegakan batu nisan miring (nisan nomor 5)
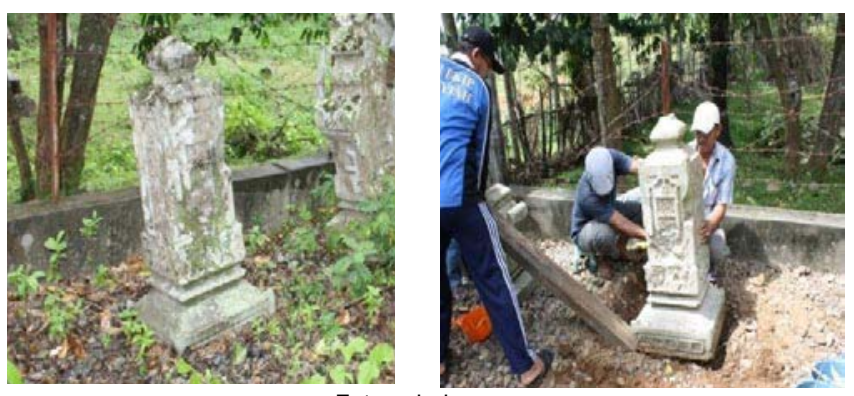

Foto sebelum
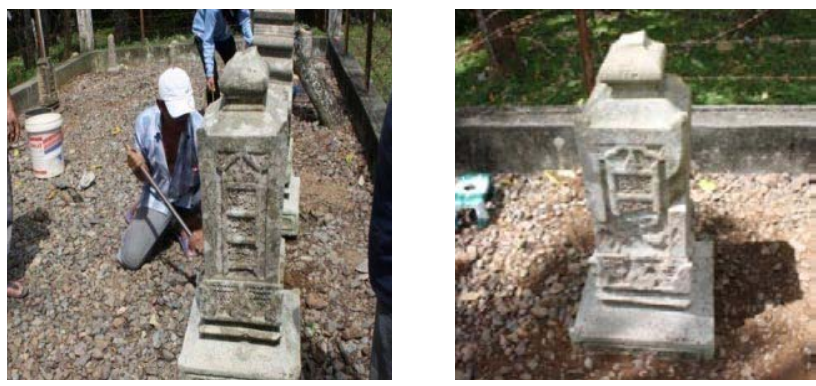

Foto setelah diperbaiki 
Foto penegakan batu nisan miring (nisan nomor 5)
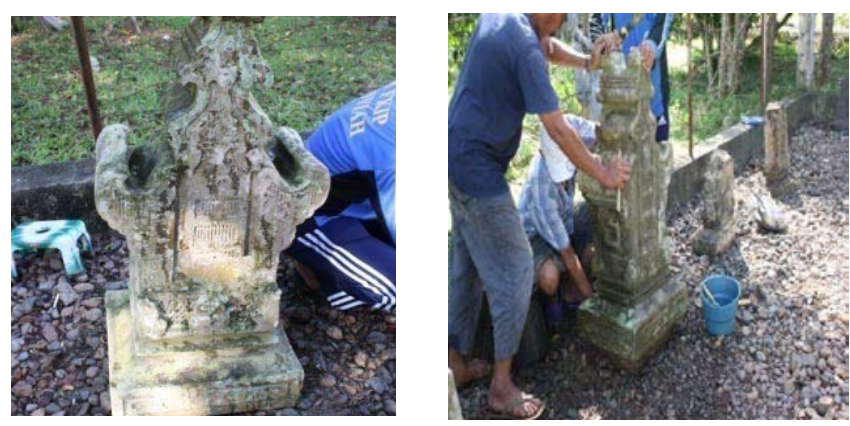

Foto sebelum
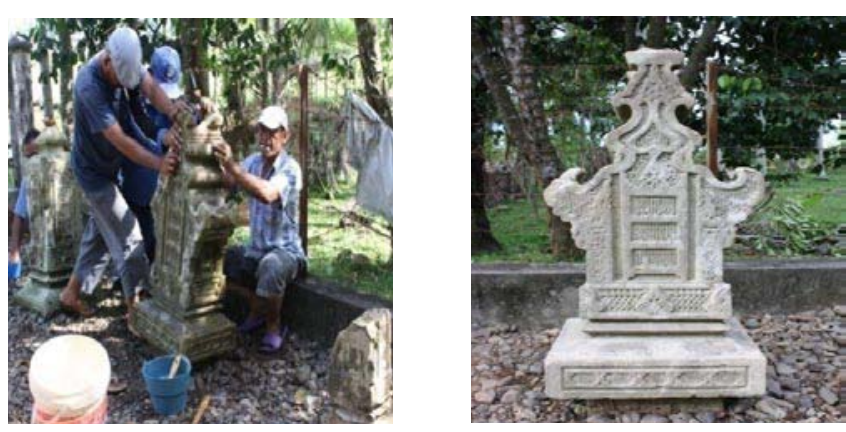

Foto setelah diperbaiki

Foto penegakan batu nisan miring (nisan nomor 1)

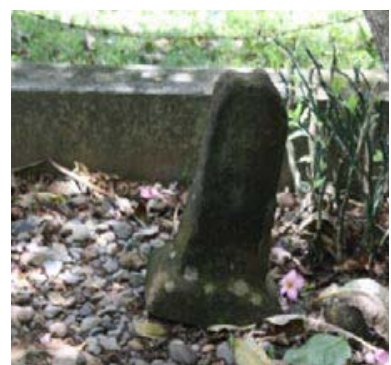

Foto sebelum

Prosedur pengerjaan penegakan nisan-nisan yang miring adalah:

menyiapkan alat yang diperlukan

menggali tanah tempat berdirinya nisan

ditegakkan dengan bantuan balok kayu.

\section{c. Pengelupasan campuran semen pasir pada nisan-} nisan di Komplek Makam Putro Balee

Pada Komplek Makam Putro Balee terdapat 4 buah nisan yang ditempel semen bercampur pasir oleh tukang pada bekas pengasahan pisau oleh penduduk sekitar (dilakukan pada saat pembuatan cungkup). Proses pengelupasan harus dilakukan dengan hati-hati agar permukaan nisan tidak ikut terkelupas. Peralatan yang digunakan adalah sebagai berikut:
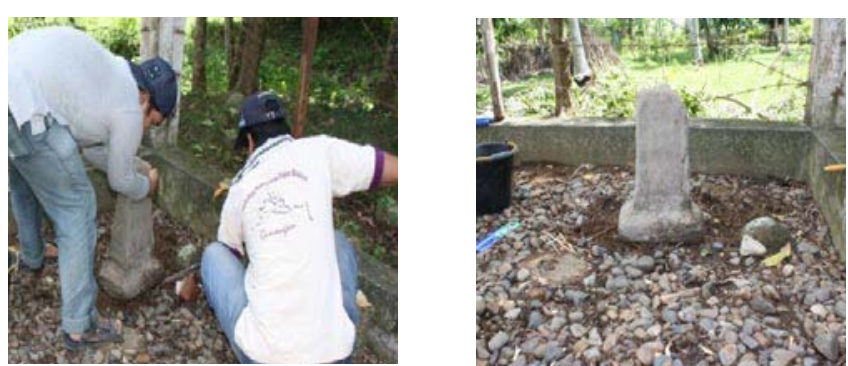

Foto setelah diperbaik
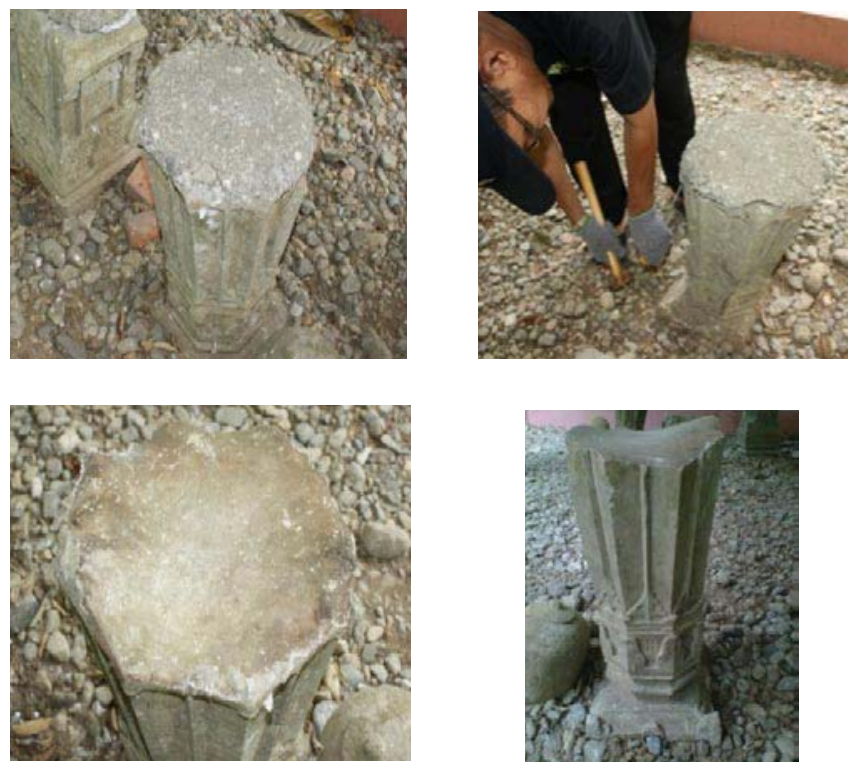

Foto nisan nomor 2

- Palu sedang

- Pahat
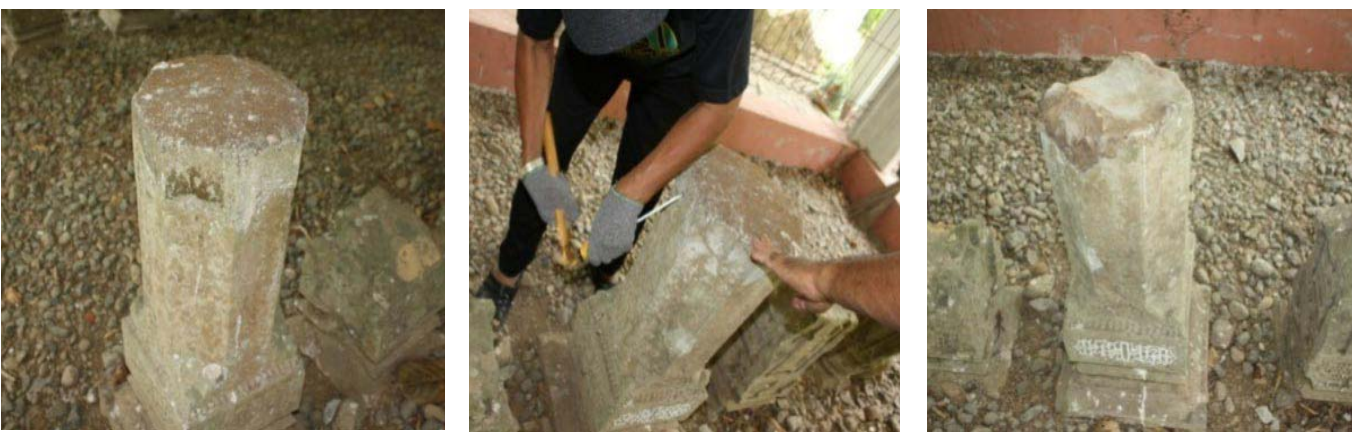

Foto nisan nomor 3 
Prosedur pengerjaan pengelupasan semen yang tertempel pada nisan-nisan adalah:

- menyiapkan alat yang diperlukan

- memahat bagian semen dengan pelan-pelan

- bagian semen yang terkelupas diangkat

\section{Penutup}

Tindakan yang dilakukan dalam kegiatan konservasi ini sangat sederhana. Hal ini dilakukan untuk mengurangi resiko dengan hasil memaksimal mungkin dan dalam pelaksanaannya harus memperhatikan kaidah-kaidah yang berlaku secara teknis dan arkeologis. Tindakan ini juga dilakukan untuk menghambat proses pelapukan agar umur nisan-nisan tersebut dapat lebih diperpanjang untuk generasi yang akan datang.

Kerusakan yang terdapat pada Komplek Makam Putro Balee dan Komplek Makam Tgk. Awe Geutah hampir sama yaitu kerusakan yang diakibatkan oleh alam dan manusia. Kerusakan yang paling menonjol adalah

\section{Daftar Pustaka}

BP3. 2012. "Laporan Teknis Konservasi Komplek Makam Putro Balee, Makam Tgk. Aer Chan dan Makam Tgk. Awe Geutah di Kabupaten Pidie, Prov.insi Aceh.

Cahyandaru, Nahar. 2010. "Dasar-dasar Konservasi”, Artikel dalam Bimbingan Tenaga Teknis Konservasi Tingkat Dasar. Magelang : Balai Konservasi Peninggalan Borobudur.

Kementerian Kebudayaan dan Pariwisata. 2005. "Pedoman Perawatan Dan Pemugaran Cagar Budaya Bahan Batu", Jakarta.

Munandar, Aris. 2006. Kerusakan dan Pelapukan Material. Magelang : Balai Konservasi Peninggalan Borobudur. batu nisan patah, gempil, retak, aus dan kerusakan yang yang diakibatkan oleh mikroorganisme seperti jamur, lichen dan lumut. Sisa batu nisan yang patah tidak ditemukan lagi di situs, kemungkinan dibawa oleh penduduk sekitar untuk dijadikan batu asah, sehingga tidak bisa dilakukan penyambungan pada nisan-nisan yang patah dan gempil. Kegiataan konservasi ini dilakukan untuk mengurangi pelapukan pada batu-batu nisan, menyambung batu nisan yang patah, menegakkan batu nisan yang miring dan melesak, membersihkan semen yang ditempel dan membersihkan dari kotoran yang menempel sehingga bermanfaat pada pembacaan kaligrafi yang lebih jelas. Pada nisan-nisan yang patah dan retak diadakan perbaikan berupa pengeleman tanpa angkur dan pengeleman dengan angkur. Pengeleman tanpa angkur digunakan pada nisan-nisan yang retak, gempil dan tingkat kerusakannya kecil, sedangkan pengeleman dengan angkur dilakukan pada nisan-nisan yang patahannya besar dan tingkat kerusakannya besar.

Munandar, Aris. 2010. Kerusakan dan Pelapukan Bahan Batu. Magelang : Balai Konservasi Peninggalan Borobudur.

Suaka Peningggalan Sejarah dan Purbakala Prov. Aceh Sumut. 1994. " Laporan Pendataan Situs/ Bangunan Peninggalan Sejarah dan Purbakala di Kabupaten Pidie".

"Undang-undang Republik Indonesia Nomor 11 Tahun 2010 Tentang Cagar Budaya” 